Instructions for authors, subscriptions and further details:

http://rasp.hipatiapress.com

\title{
Hibridador/hibridadora $@$
}

Marta Negre \& Àngels Viladomiu ${ }^{1}$

1) Artistas y profesoras. Facultad de Bellas Artes. Universidad de Barcelona. España

Date of publication: February $3^{\text {rd }}, 2017$

Edition period: November 2016 - February 2017

To cite this article: Negre, M., \& Viladomiu, A. (2017). Hibridador/hibridadora. Barcelona, Research, Art, Creation, 5(1), 14-16. doi: 10.17583/brac.2017.2281

To link this article: http://dx.doi.org/10.17583/brac.2017.2281

\section{PLEASE SCROLL DOWN FOR ARTICLE}

The terms and conditions of use, except where otherwise noted, are related to the Open Journal System and to Creative Commons Attribution License (CC-BY-NC-ND). 
hibridador/hibridadora

$<$ Ciències de la vida > <Professions $>$

Persona especialitzada en la producció d'hibrids a partir d'individus d'espécies distintes d'una manera artificial.

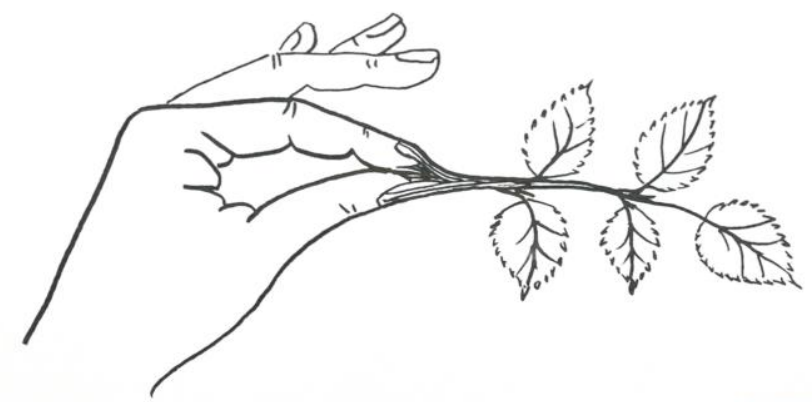




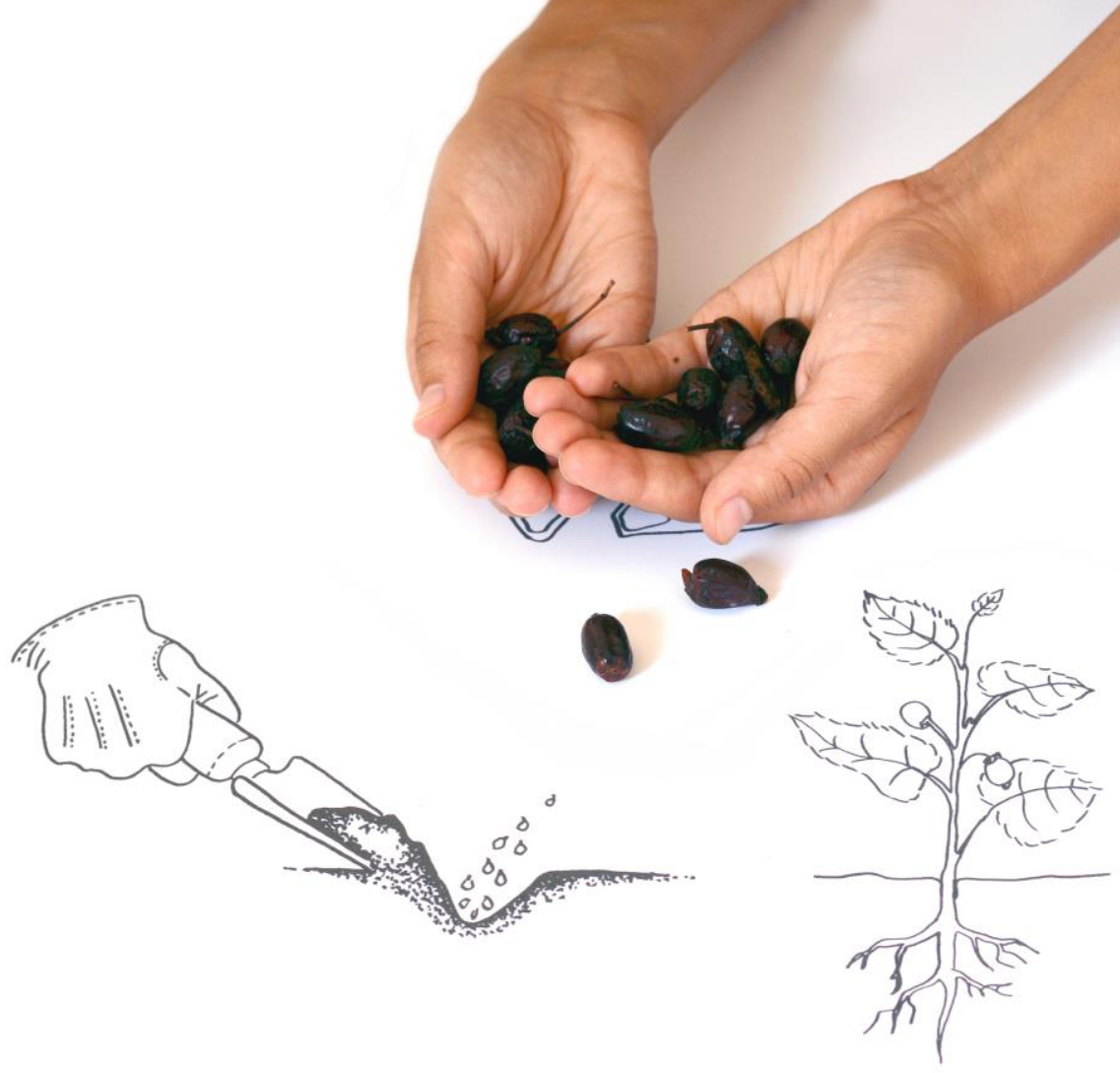

Fases del procés d'obtenció de l'híbrid contemporani

1. Escollir l'espècie A per ser fecundada, treure'n els pètals i els estams.

2. Tallar un exemplar B, d'on obtindrem el pol-len per pol-linitzar A.

3. Construir una incubadora de paper en forma de cucurutxo. Introduir A i

B en la incubadora, esperar que la temperatura sigui idònia i que el trànsit de partícules estimuli la fecundació automàtica.

4. Un cop A ha estat fecundada, esperar la producció de fruits.

5. Extreure les llavors del fruit i sembrar-les. Esperar que creixi Xab.

6. Empeltar l'ullet de Xab en un peu de gavarrera, lligar-ho i protegir-ho

amb cinta d'emmascarar. Anotar l'encreuament i esperar pacientment el resultat. 


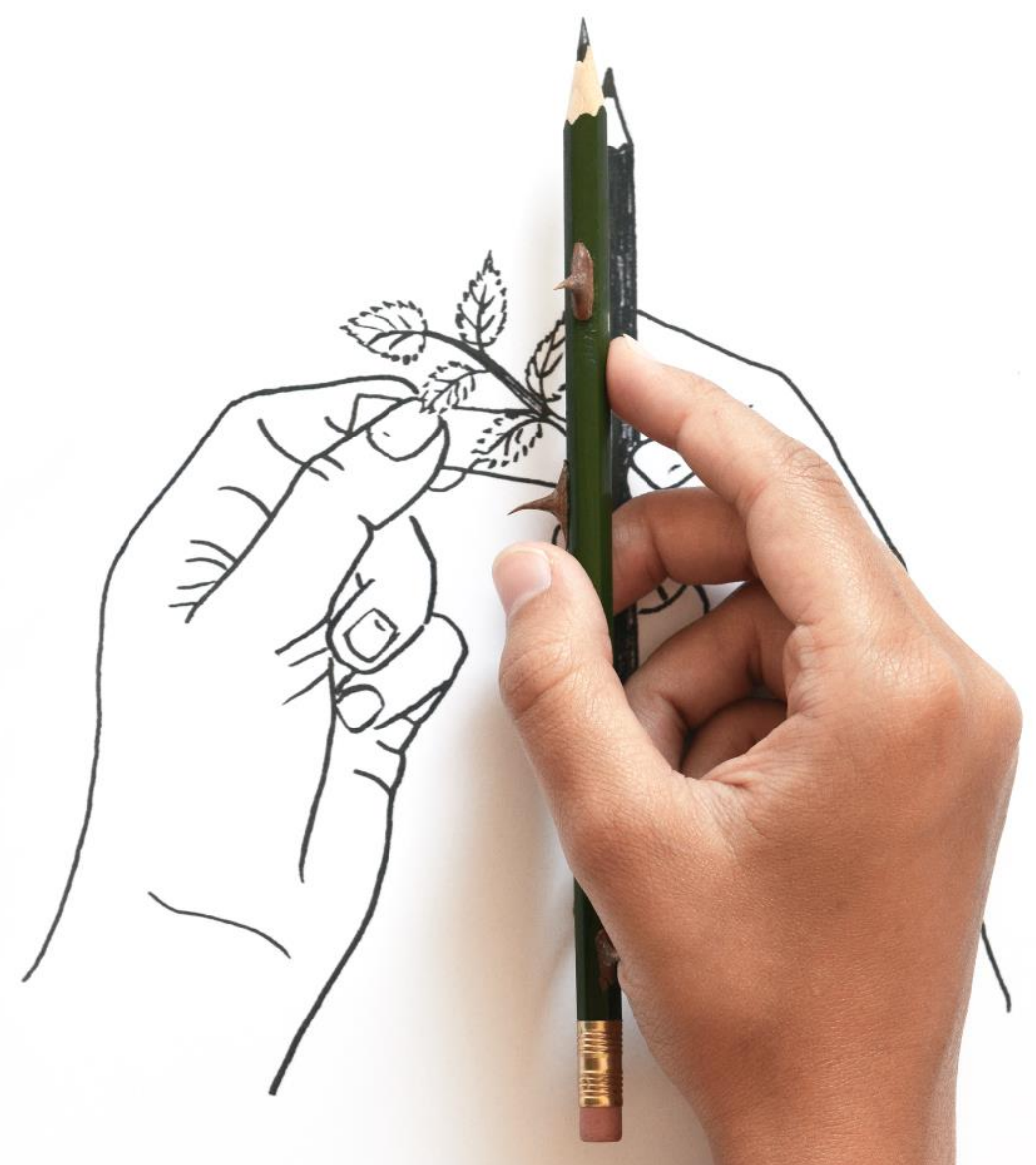

